\title{
Head and Neck Pathology: New Developments in the Diagnosis and Pathogenesis of Head and Neck Tumors
}

\author{
Stefan E. Pambuccian, ${ }^{1}$ Edward B. Stelow, ${ }^{2}$ Ioannis G. Koutlas, ${ }^{3}$ and Michael J. Thrall ${ }^{4}$ \\ ${ }^{1}$ Department of Laboratory Medicine and Pathology, University of Minnesota, Minneapolis, MN 55455, USA \\ ${ }^{2}$ Department of Pathology, University of Virginia Charlottesville, VA 22908, USA \\ ${ }^{3}$ Division of Oral Pathology, University of Minnesota, Minneapolis, MN 55455, USA \\ ${ }^{4}$ Department of Pathology and Laboratory Medicine, Weill Medical College of Cornell University, \\ The Methodist Hospital Physicians Organization, Houston, TX 77030, USA
}

Correspondence should be addressed to Stefan Pambuccian, pambu001@umn.edu

Received 4 December 2011; Accepted 4 December 2011

Copyright (c) 2011 Stefan Pambuccian et al. This is an open access article distributed under the Creative Commons Attribution License, which permits unrestricted use, distribution, and reproduction in any medium, provided the original work is properly cited.

In this issue manuscripts are presented that touch on some of the new developments in the diagnosis and pathogenesis of head and neck tumors. The first article by T. Tanaka et al. summarizes our understanding of the development of oral squamous cell carcinoma and discusses possible chemoprevention. As discussed there, the diagnosis of head and neck cancer can be limited as the entirety of the upper aerodigestive tract can be affected by smoking. P. Pujary et al. discuss the use of spectroscopy for the identification of malignant squamous mucosa.

As the incidence of smoking decreases in many parts of the world, there has been a noted decline in the incidence of smoking-related malignancies, including head and neck squamous cell carcinoma. Unfortunately, with this decline, many parts of the world have witnessed a concomitant increase in oropharyngeal squamous cell carcinomas related to high-risk human papillomavirus (HPV) infection. In this issue, Dr. F. Farshadpour et al. show, in a case control study, that oropharyngeal squamous cell carcinomas that develop in nonsmokers who do not abuse alcohol are more likely to be related to HPV infection than those that develop in smokers who do consume alcohol and confirm that the HPVrelated tumors have a better prognosis. R. L. Cantley et al. provide a nice review of the various immunohistochemical, in situ hybridization, and molecular studies that can be used to demonstrate HPV infection.

Over the past decade there have been many exciting developments in our understanding of the classification of salivary gland neoplasms and the associated genetic abnormalities. In this issue, M. Shishegar et al. describe a series of salivary gland tumors seen at their institution over a 6-year period. A. F. Costa et al. review the clinicopathologic changes associated with high-grade transformation that can be seen with adenoid cystic carcinomas, acinic cell carcinomas, epithelial-myoepithelial carcinomas, and polymorphous low-grade adenocarcinomas.

Sinonasal intestinal-type adenocarcinomas remain a pathologic enigma, sometimes associated with heavy wooddust exposure. In the final article in this issue, B. Vivanco et al. review a large series of these tumors and attempt to identify possible precursor lesions for these rare malignancies.

Stefan Pambuccian Edward B. Stelow Ioannis G. Koutlas Michael J. Thrall 


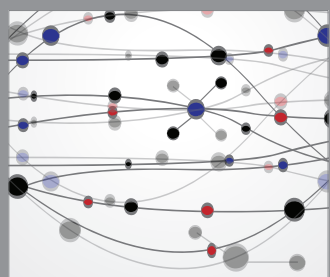

The Scientific World Journal
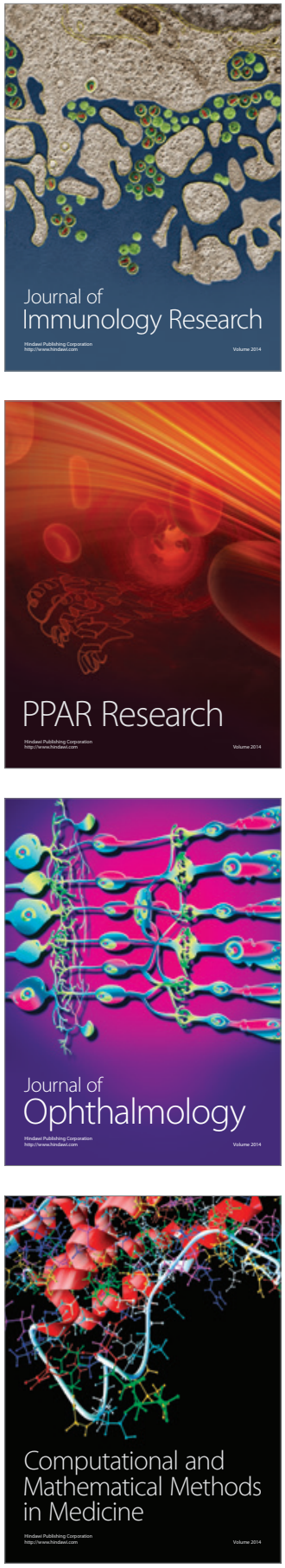

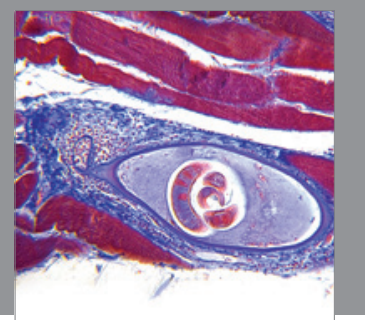

Gastroenterology

Research and Practice
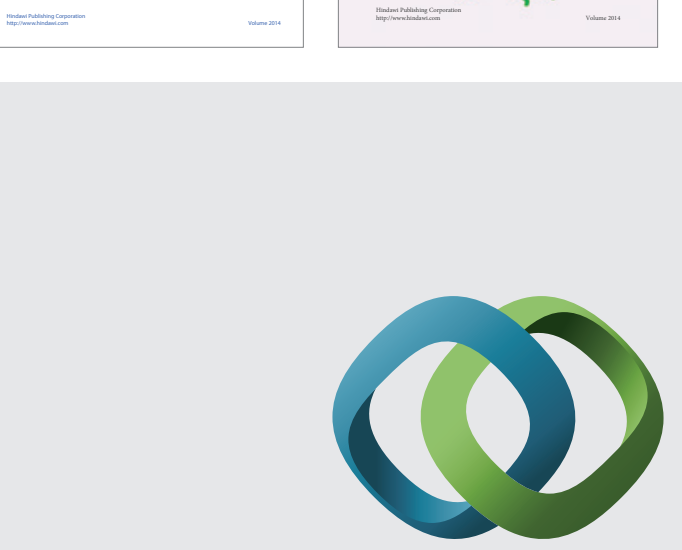

\section{Hindawi}

Submit your manuscripts at

http://www.hindawi.com
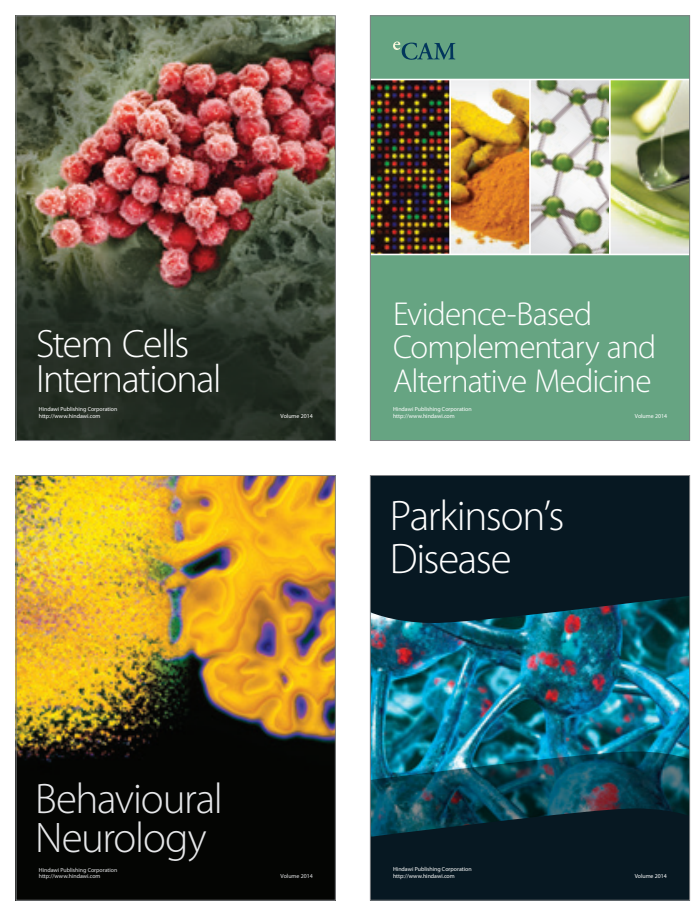

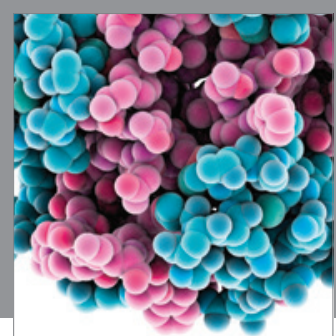

Journal of
Diabetes Research

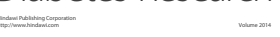

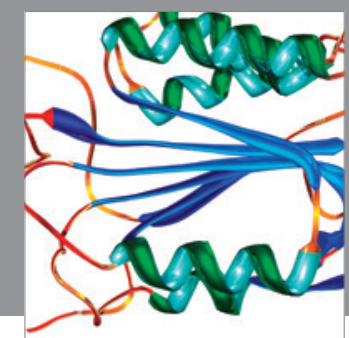

Disease Markers
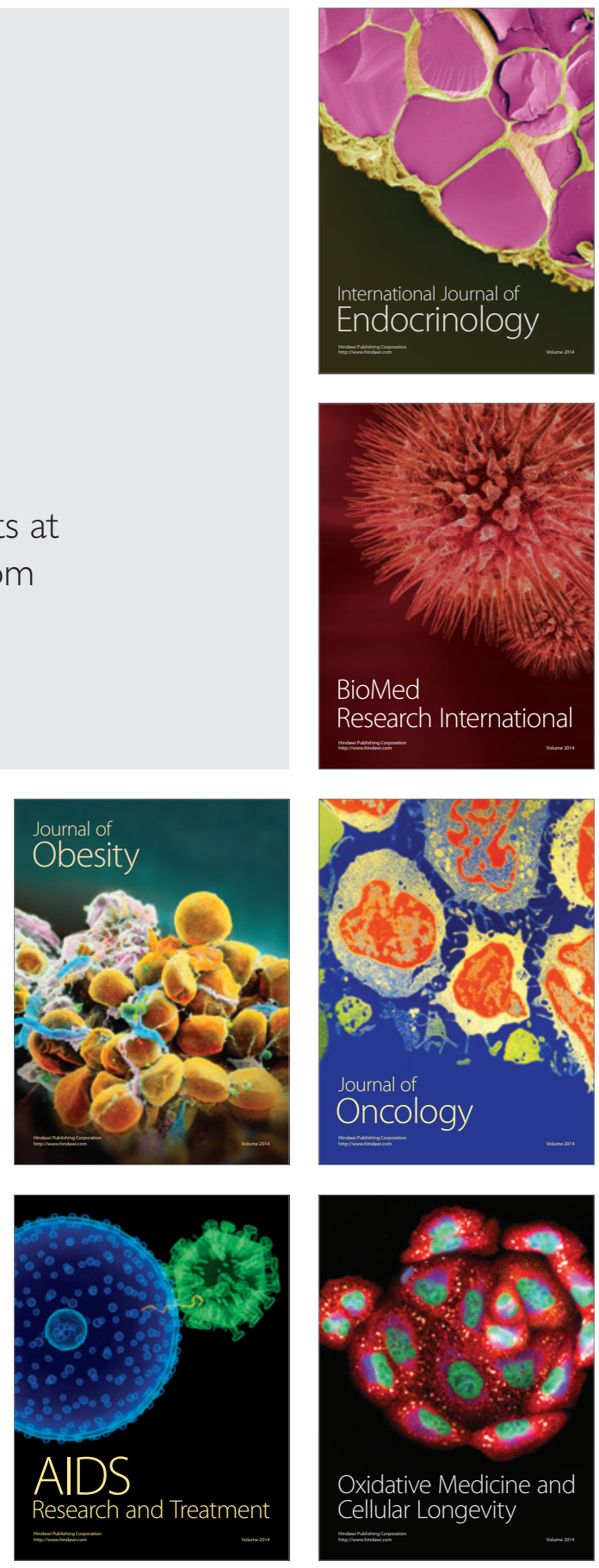